\title{
Development of environmental guidelines for electronic appliances
}

Legarth, Jens Brøbech; Alting, Leo; Erichsen, Hanne K. Linnet; Gregersen, Johan Chr; Jørgensen, Jørgen

\section{Published in:}

Proceedings of IEEE International Symposium on Electronics and the Environment

Link to article, DOI:

10.1109/ISEE.1994.337289

Publication date:

1994

Document Version

Publisher's PDF, also known as Version of record

Link back to DTU Orbit

Citation (APA):

Legarth, J. B., Alting, L., Erichsen, H. K. L., Gregersen, J. C., \& Jørgensen, J. (1994). Development of environmental guidelines for electronic appliances. In Proceedings of IEEE International Symposium on Electronics and the Environment (pp. 69-74). IEEE. https://doi.org/10.1109/ISEE.1994.337289

\section{General rights}

Copyright and moral rights for the publications made accessible in the public portal are retained by the authors and/or other copyright owners and it is a condition of accessing publications that users recognise and abide by the legal requirements associated with these rights.

- Users may download and print one copy of any publication from the public portal for the purpose of private study or research.

- You may not further distribute the material or use it for any profit-making activity or commercial gain

- You may freely distribute the URL identifying the publication in the public portal 


\title{
Development of Environmental Guidelines for Electronic Appliances. ${ }^{1}$
}

\author{
Jens Legarth, Leo Alting, Hanne Erichsen, Johan Gregersen and Jørgen Jørgensen \\ The Life Cycle Centre, Institute for Product Development \\ Building 403, The Danish Technical University \\ DK-2800 Lyngby, Denmark.
}

\begin{abstract}
This paper presents a general method for the development of environmental guidelines for complex products. The method is based on the life cycle concept. The application of life cycle assessment methods reveals the peak environmental impacts, and their source resulting in environmental guidelines uniquely suited for the type of product in focus. Two product cases are discussed.
\end{abstract}

\section{INTRODUCTION.}

Conservative estimates of world population growth and the growth in world economy foretell a doubling of world population and a five-time increase of world economy by the year 2050 [1]. This development will cause a dramatic rise in the demand for complex industrial products such as cars and electronics, accompanied by an increase in the consumption of natural resources. Today consumption of resources and the production and use of complex products are associated with a wide span of environmental impacts from the extraction of raw materials and energy carriers to the disposal of the products, and an uncritical scale-up of these activities with growth in population or economy will have devastating effects on the environment.

In order to avoid environmental problems of an unprecedented scale and to preserve natural resources for the generations to come, what has become known as a sustainable development is now being incorporated into all areas of human activity, not least the development of complex industrial products, of which the larger part rely on electricity to function. In product development the basis for a sustainable development is the holistic life cycle concept, according to which a product should be seen as having five life cycle phases: A pre-production raw material extraction phase, a component and product production phase, a distribution/transport phase, a use phase and a disposal/recycling phase.

Full-blown life cycle assessments are used in product development to set initial environmental standards for a new product, and they are used to evaluate the environmental impact of the final product. However, in between, the product development team will have to rely largely on other tools in order to meet the new challenge of design for environment. One such tool is a set of guidelines (check-lists, rules or procedures), directed towards improving the environmental performance of the product in all life cycle phases. The development of such guidelines has to take place on the basis of the life cycle concept, since only a holistic approach can reveal the true environmental consequences.

\section{MAPPING LIFE CYCLES}

Before the details of the method for generation of guidelines are discussed it is important to understand what a life cycle is. Figure 1 below pictures a life cycle as it would look for most electrical and electronic products.

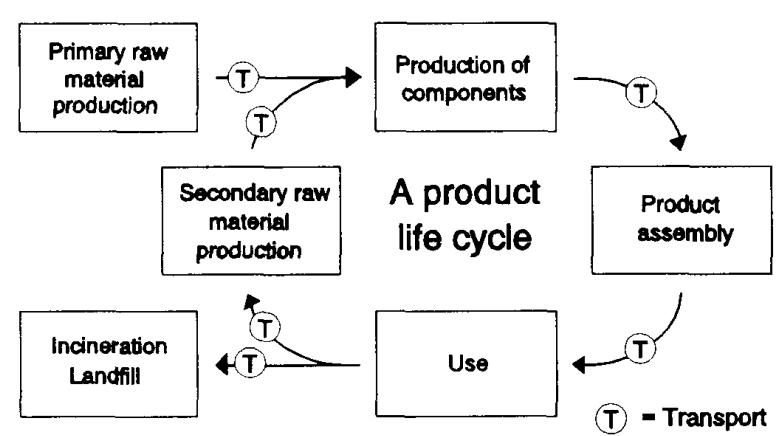

Fig. 1. A product life cycle.

The phases are as described in the previous section. Please note that the distribution/transport phase is not a discrete phase, but an abstract phase with elements from the entire life cycle.

In describing a product life cycle in the context of product development, the focal point is the production phase. The manufacturer knows this phase the best, and a detailed decription of the production is the starting point of a product life cycle assessment. The product that is selected as the case for which the guidelines should be developed, is described as a list of the components that make up the

\footnotetext{
1 The project was sposored by the Danish National Environmental Protection Agency
} 
product. This list most manufacturers have readily available.

The material composition of the product is estimated from the component list. In order not to loose oneself in the quite comprehensive data collection this may involve, criteria can be set for how detailed the description should be. In the two product cases we have worked with (a SMD-based hand portable telephone and a frequency converter based on power electronics), we have operated with a limit: All components weighing more than one per cent of the total product weight should be described, whereas components weighing less that one per cent of the total product weight should only be described if it is known that they contain environmentally relevant materials, such as toxic elements or materials, where production is highly energy consuming. In this way respectively 94 and 97 per cent of the products weights were accounted for. The products material compositions are given in figures 2 and 3 [2] [3].

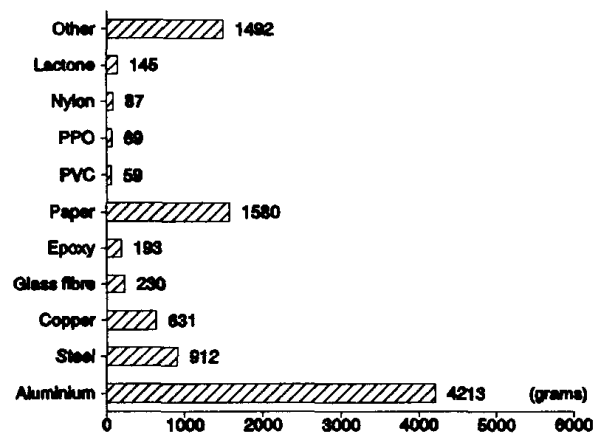

Fig. 2. Materials in a frequency converter with packaging.

The material analysis is relevant for both the pre-production raw materials extraction scenario and for the postproduction disposal/recycling scenario. Data for the environmental impacts and energy consumption (with corresponding impacts from energy production) from the production of the raw materials used in the product, constitutes the data basis representing the raw material extraction life cycle phase. Further, a material flow is the back-bone for the assessment of the environmental impacts from disposal in a landfill or an incineration plant, or from the recycling of some of the materials from the product.

The production process-sequence is then mapped and each so-called unit process is investigated with respect to waste generation, emissions and energy and water con-

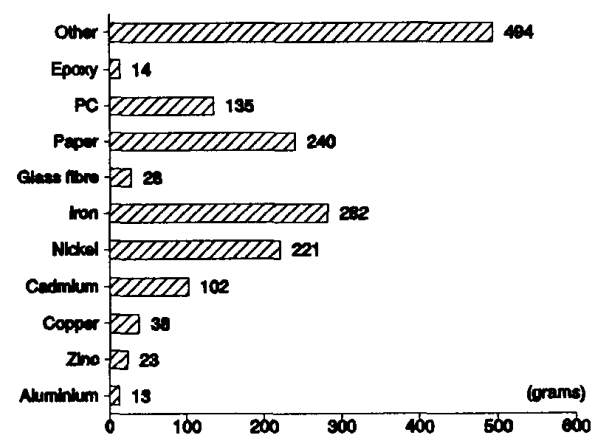

Fig. 3. Material composition of a portable telephone with averagely 6.1 NiCd batteries.

sumption. Of particular interest is the generation of waste in the production of printed circuit boards, where components are followed by a relatively large amount of packaging, and where a large fraction of the board laminate is cut away. The amount of packaging waste amounts to 4 weight per cent of the product weight for the frequency converter and no less than 27 weight per cent of the product weight for the portable telephone. There is thus a great difference between the relative packaging consumption in more conventional pcb production and in SMDbased pcb production.

Relatively large amounts of the pcb laminate are cut away when the pcb is shaped out of the standard format. For the portable telephone 46 weight per cent of the laminate is wasted even with material saving water cutting.

The energy consumption in production is divided into consumption of energy in the production processes and consumption of energy for heating, light etc., the so-called comfort energy. For the power electronic based frequency converter the total energy consumption is $59 \mathrm{kWh}$ per product, with 70 per cent process energy and 30 per cent comfort energy. For the portable telephone the total energy consumption is $20 \mathrm{kWh}$ per piece, with 10 per cent process energy and 90 per cent comfort energy. The reason for the relatively high process energy consumption for the frequency converter is that the burn-in test for power electronics is very energy consuming.

In the pre-production raw material extraction phase, the largest environmental impacts normally stem from the consumption of energy. Depending on the energy consumption and the amount of various materials neccesary to produce a component, one can speak of more or less 
environmentally friendly raw materials. And, when looking at real life scenarios, copper produced in USA may be more environmentally friendly than copper produced in the Far East. Environmentally relevant data (energy consumption, emissions etc.) are now being made available in various life cycle data bases, and it is today a somewhat less time consuming task to assess the environmental impacts in the raw material extraction phase.

The important key to approaching the post-production phases, use and disposal/recycling is the so-called export scenario. The manufacturer will have (often confidential) information about where their products are sold, and this information opens up for a detailed assessment of the typical average use sitaution and the typical disposal/recycling situation: Most companies have a good knowlegde about how their products are used in various countries, what the energy consumption is, life span, the consumption of help materials as e.g. batteries, lubricant, water etc., and it is possible to estimate an average disposal situation from detailed knowlegde of how products are disposed of in the relevant countries.

The detailed knowlegde of the average use-situation facilitates an assessment of the environmentally relevant data, for electronic appliances above all the consumption of energy. The energy consumptions of the two products are shown in figures 4 and 5 . The consumption is divided into life cycle phases, the production phase being further subdivided into comfort and process energy consumptions.

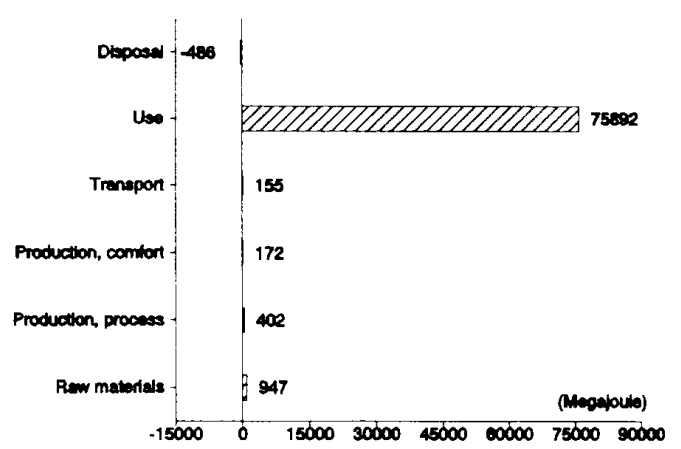

Fig. 4. Energy consumption by a frequency converter in its life time.

Please note that there is an energy gain in the disposal phase because energy is recovered from plastics and paper in incineration plants.

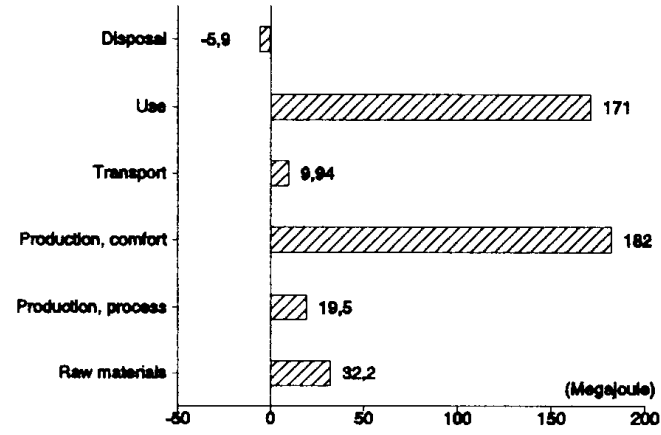

Fig. 5. Energy consumption of a portable telephone in its life time.

It is typical for electrical and electronic products that the larger energy consumption is in the use phase, because the products rely on electricity to function. There is, however, a great difference in the total energy consumption between the two products. The reason for the large energy consumption of the industrially orientated power product is an efficiency in converting electricity which is $96 \%$. (It should be noted that a frequency converter is in fact essentially an environmentally friendly product, because its very use saves relatively large amounts of energy, namely ca. $163 \mathrm{GJ}$ in a life time of 10 years compared to the energy consumption of ca. $76 \mathrm{GJ}$ in the use phase in figure 4.)

In short to map a life cycle, focus on the material composition of the product. Use this knowlegde to assess the raw material extraction scenario from available data bases. An export scenario and knowlegde of the use-situation and the disposal situation in the various countries gives you the post-production phases. The production phase itself is investigated by making a map of the production unit processes and assessing all inputs and outputs.

\section{QUANTIFYING ENVIRONMENTAL EFFECTS}

Not only the production phase but in fact the entire life cycle may be viewed as a sequence of unit processes. In the data collection step of a life cycle assessment, each life cycle unit process is in principle investigated and emissions to land, water and air, energy consumption and consumption of materials are quantified. The result is a comprehensive list of all inputs and outputs from the life cycle, the so-called inventory. 
In the life cycle assessment method of the Life Cycle Centre, this list is translated into objective quantitative measures of environmental effect through steps of classification, standardization and normalization [4] [5] [6].

Emissions of substances to land, water and air from the processes in the life cycle are classified according to the environmental effects they contribute to. The effects covered by the Life Cycle Centre in the up-to-date version are divided into global effects (global warming, ozone depletion), regional effects (acidification, eutrophication, regional toxicity and photochemical ozone creation) and local effects (local toxicity, area degradation).

Classified emissions are put on a standard form by expressing their effects in terms of an amount of a relevant reference substance. The reference substance is $\mathrm{CO}_{2}$ for global warming, CFC-11 for ozone depletion, and so on. In performing the standardization, the total amount of emissions contributing to the effect in focus are expressed in terms of one number, namely the corresponding emission of the reference substance.

In order to be able to compare individual effects, the standardized data are further normalized by dividing with a reference emission. For global warming the reference emission is the amount of so-called $\mathrm{CO}_{2}$-equivalents emitted in the world per year per world citizen. In this way the products total contribution to global warming can be expressed as a number of so-called person equivalents. The same methodology applies to the other environmental effects, where regional reference emissions are used for regional effects and local reference emissions are used for local effects.

The inventory data are now expressed in terms of a number of person equivalents for each environmental effect. The translation is both scientifically based and fully objective. The resulting eco-profile may be subsequently evaluated scientifically or politically, but the process of generating it is purely objective.

\section{ECO-PROFILES.}

The eco-profiles resulting from the translation of inventory data form the basis for the methodological development of guidelines. Elements of eco-profiles for the two product cases are presented in figures 6 and 7. The data presented are based on an analysis of the life cycle for the two products, but they do not include the disposal phase and only the most relevant global and regional effects are dealt with. The quantified contributions to the four most relevant effect types are divided into the four phases covered by the analysis.

There is no contribution to stratospheric ozone depletion from the two products, because the practice of cleaning printed circuit boards with CFC has been abandoned. Had the practice been kept, the contribution to ozone depletion would e.g. for the portable telephone have been ca. 6.800 person equivalents, an effect that would dwarf all other impacts completely (compare with figure 7). This reveals quite well how important the ban on CFCs is.

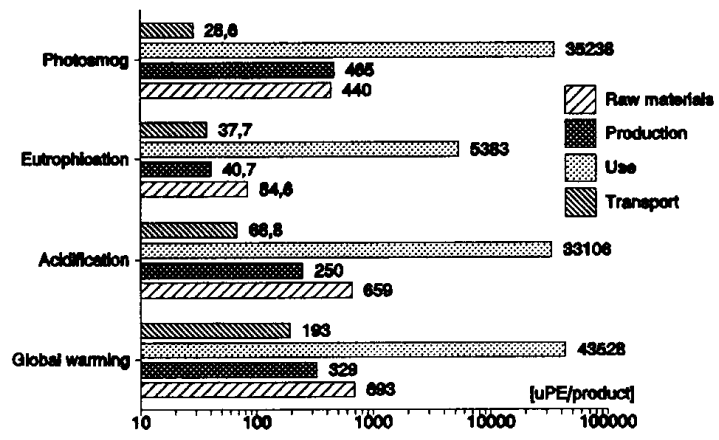

Fig. 6. Elements of an eco-profile for a frequency converter.

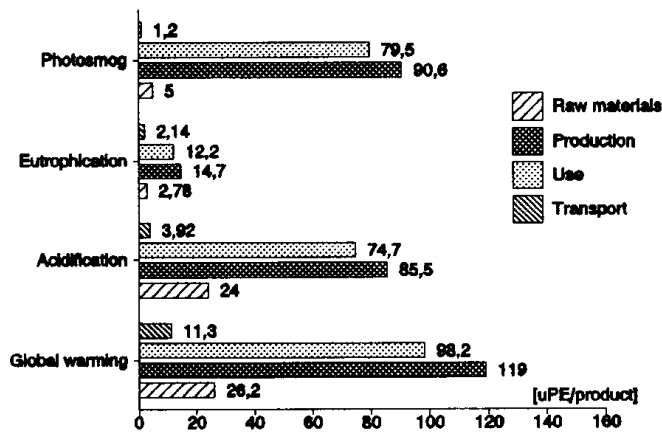

Fig. 7. Elements of an eco-profile for a portable telephone.

In the present work it has been chosen not to include the production of the components into the analysis because environmentally relevant data are not available. When focusing on the assembly of components, which in itself is a practically no-emission procedure, by far the largest impacts from the life cycle comes from the production of energy. There is thus a close correlation between energy consumption profiles and eco-profiles. 


\section{DEVELOPING GUIDELINES.}

The eco-profiles obtained through mapping and quantifying environmental impacts from all life-cycle phases forms the basis for developing environmental guidelines. The mapping reveals the potential high-impact life cycle elements, and the element specific approach allows us to pin-point exactly what is the cause of the impacts. This process of linking peak environmental impacts directly to their source is the crusial part of developing environmental guidelines, and the transcription of the knowledge gained into environmental guidelines is a comparatively simple matter.

In figure 6 it is clear that by far the largest impacts from a frequency converter stem from the use phase. The use phase impacts in turn stem from the energy consumption alone, and can only be reduced if a higher efficiency of converting electricity is achieved. So the most important over-all environmental guideline for a frequency converter is to achieve the highest possible efficiency. This over-all principle leads to a number of technology specific guidelines, as e.g.: Use components with a low resistance.

Today much work is centered around achieving higher efficiencies, and the development of superconducters will be a breakthrough, not only technologically but, as it appears, also environmentally. An important guideline is to take advantage of new technological developments.

Achieving higher efficiencies should be a primary concern. However, when this is achieved, the next major impacts should be looked into. As shown in figure 6 the second-most important impacts stem from the raw material extraction phase. Investigating the data basis of the ecoprofile reveals that these impacts in turn stem from the use of aluminium as a casing. So a simpel guideline could be: Do not use aluminium as a casing. This is, however, an over-simplfied wiev, as the aluminium is chosen because of its heat transfering effect, and the alternative could in this case be to build in an energy consuming fan. (The life cycle concept can and shall also be used to evaluate technological alternatives.) In stead the guideline should be to look for new less energy intensive construction materials.

For the hand portable telephone - figure 7 , the major impacts come from the comfort energy consumption and from the energy consumption in the use phase. It is an interesting result that the production of SMD-based electronics is so much less energy intensive that the comfort energy consumption largely exceeds the process energy consumption. In fact major improvements can be made without altering the product and the production at all. To produce a more environmentally friendly SMDbased product, important over-all guidelines are to lower the comfort energy consumption and to use more environmentally friendly energy sources for heating.

That the energy consumption in the use phase is a major determinant of environmental performance is a typical result, which is seen with all products that rely on electricity to function. Probably the most important over-all environmental guideline is to reduce the energy consumption in the use of the product. This can be done in any number of ways, depending on the product in focus. For the portable telephone important factors are to increase efficiency in power amplifying and to make use of the possibility to transmit digitally in time-slots.

The production of components is not dealt with in the investigation, mostly because it is so difficult to get environmentally relevant data from the manufacturers of components. For this reason the analysis does not produce guidelines for the choice of electronic components. However, this is a most interesting field, which must be dealt with in the future.

\section{SUMMARY}

Product development teams will have to take a pro-active stand to meet the new challenges of design for environment, and they will need new tool in order to do so. One such tool is a set of environmental guidelines, developed on the basis of the holistic product life cycle concept.

Developing these guidelines involves a qualitative mapping of the life cycle of the product in focus, with a subsequent quantitative description of environmentally relevant parameters in the so-called inventory.

Through steps of classification, standardization and normalization, the inventory data are translated into an objective eco-profile. The eco-profile reveals the peak environmental impacts, and the detailed knowledge of whai causes the impacts can be transcribed into a set of environmental guidelines for the product type in focus. For electronic appliances, the guidelines primarily deal with reducing energy consumption in all life cycle phases.

\section{ACKNOWLEDGMENT.}

The authors would like to thank the Danish companies Danfoss $\mathrm{A} / \mathrm{S}$ and Dancall A/S for their collaboration. 


\section{REFERENCES}

[1] The World Resources 1992-93. The World Resources Institute Oxford University Press, 1992.

[2] Danfoss A/S, Gråsten, Denmark. Private correspondance.

[3] Dancall Radio A/S, Pandrup, Denmark. Private correspondance.

[4] L. Alting and J. Jørgensen, The Life Cycle Concept as Basis for Sustainable Industrial Production. The Annals of the CIRP Vol. 42/1/1993.

[5] H.W. Christensen, Environmental Analysis in Product Development. Internal report 1993 (in Danish).

[6] L. Alting, J. Jergensen and H.W. Christensen, Product Life Cycle Assessment as a Decision Making Tool in Product Development. IEEE International Symposium on Electronics and the Environment, May 2-4, 1994, USA. 